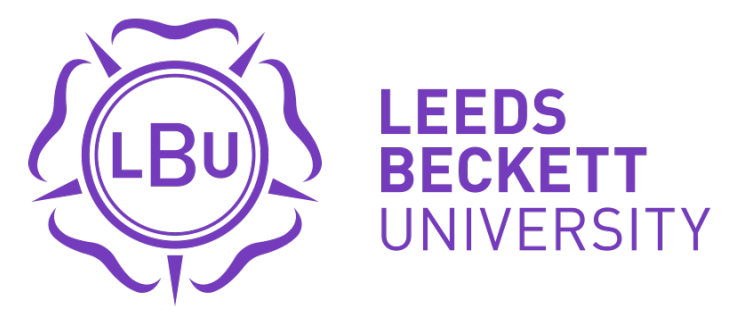

Citation:

Cartwright, AJJ and Roach, J and Armitage, R (2019) Mission impossible? Assessing the veracity of a mental health problem as result of a road traffic accident: a preliminary review of UK experts' practices. Journal of Forensic Psychiatry and Psychology, 30 (1). pp. 89-111. ISSN 1478-9957 DOI: https://doi.org/10.1080/14789949.2018.1502338

Link to Leeds Beckett Repository record:

https://eprints.leedsbeckett.ac.uk/id/eprint/5141/

Document Version:

Article (Accepted Version)

The aim of the Leeds Beckett Repository is to provide open access to our research, as required by funder policies and permitted by publishers and copyright law.

The Leeds Beckett repository holds a wide range of publications, each of which has been checked for copyright and the relevant embargo period has been applied by the Research Services team.

We operate on a standard take-down policy. If you are the author or publisher of an output and you would like it removed from the repository, please contact us and we will investigate on a case-by-case basis.

Each thesis in the repository has been cleared where necessary by the author for third party copyright. If you would like a thesis to be removed from the repository or believe there is an issue with copyright, please contact us on openaccess@leedsbeckett.ac.uk and we will investigate on a case-by-case basis. 
MISSION IMPOSSIBLE?

Mission impossible? Assessing the veracity of a mental health

\section{problem as result of a road traffic accident: a preliminary review of UK experts' practices}

1. Dr Ashley Cartwright, School of Social Science, Leeds Beckett University, Leeds, LS1 3HE

Email. a.j.cartwright @leedsbeckett.ac.uk

Tel. 01138127172

Twitter. @DrAshCartwright

ORCID. 0000-0002-5331-5757

2. Dr Jason Roach, Applied Criminology Centre, University of Huddersfield, Huddersfield, HD1 3 $\mathrm{DH}$

Email. J.roach@hud.ac.uk

Tel. 01484473842

Twitter. @jrro47

3. Professor Rachel Armitage, Secure Societies Institute, University of Huddersfield, Huddersfield, HD1 3DH

Email.r.armitage@hud.ac.uk

Tel. 01484505668

Twitter. @DrRArmitage 
MISSION IMPOSSIBLE?

\title{
Mission impossible? Assessing the veracity of a mental health problem as result of a road traffic accident: a preliminary review of UK experts' practices
}

\begin{abstract}
The number of people claiming for personal injury after being involved in a road traffic accident (RTA) in the United Kingdom continues to soar. In April 2015, the UK Government intervened to implement measures aimed at reducing the prevalence of fraud within such personal injury claims. However, these reforms did not include claims for mental disorder that arise because of a RTA despite being responsible for substantially larger pay-outs in comparison to claims for whiplash. The present study examines the assessment practice for detecting fraudulent claims of this nature using a mixed methods survey analysing UK medicolegal professionals' assessment methodologies $(N=37)$. The findings suggest comprehensively that assessment practices in this field are idiosyncratic. The findings evidence limitations in all aspects of the assessment process from medico-legal assessors being asked to undertake examinations without the presence of medical records to $44 \%$ of examiners being unaware of the three types of malingering. The article concludes with recommendations for improving both assessments and the assessment process for assessing RTA claimants in the UK.
\end{abstract}

Keywords: Malingering, Psychiatry, Forensic Psychology, Psychometric Assessment, Civil Litigation

Mission impossible? Assessing the veracity of a mental health problem as result of a road traffic accident: a review of UK experts' practices 
MISSION IMPOSSIBLE?

\section{Introduction}

From 2006 to 2011 in the UK, the number of Road Traffic Accidents (RTA) reduced by $20 \%$ yet the number of personal injury claims because of such accidents increased by $60 \%$ (Merten, Dandachi-Fitzgerald, Hall, Schmandd, Santamariae \& Gozalez, 2013). In response to the rise in claims, the UK Government's select Transport Committee instigated an inquiry into the issue of claiming for personal injury following RTAs, the findings of which suggest fraudulent claiming for whiplash is a serious problem in the UK (Transport Committee, 2013). Not only are fraudulent claims for personal injury following car accidents the costliest (ABI, 2012), they also contribute to UK car insurance customers' premiums on average rising by around $£ 50$ a year (ABI, 2012).

Unsurprisingly the whiplash 'epidemic' became a focus of the UK government's agenda; in April 2015, the government's reforms to tackle the issue were implemented. The first reform was a system called MedCo (MedCo, 2015; Laws, 2015). MedCo was implemented to reduce what the Government perceived to be huge problem within the industry and this stems not just from the fraudulent claimants but the Medical Reporting Organisations (MRO) and solicitors who make a living from assessing and processing such claimants. The MedCo system was designed to remove financial links between those who refer a claimant for an assessment and those who complete the assessment (Laws, 2015). In addition, MedCo is designed to regulate those who complete such assessments by ensuring only suitably qualified professionals receive referrals to assess claimants in pursuit of financial compensation for whiplash (Laws, 2015). Furthermore, the MedCo online portal randomly assigns claimants to a medico-legal assessor, thus removing the financial link between the instructing party and the medico legal clinician. 


\section{MISSION IMPOSSIBLE?}

The UK Government did not stop with MedCo, in April 2015 they also changed the law. Section 57 of the Criminal Justice and Courts Act was amended to provide the court with the power to throw out a claim at the start of the proceedings where a claimant has been proven to be 'fundamentally dishonest' (CJCA, 2015). The new legislation suggests that an entire claim be thrown out of court unless this would cause substantial injustice to the claimant (CJCA, 2015). According to Chris Grayling - UK Secretary of State for Justice between 2012 and 2015, the reforms set by the Government were designed to strengthen the law so that removal of a claim in its entirety in cases where the court is content that the claimant has been fundamentally dishonest will now become the norm (Grayling, 2014). Whether the reforms discussed above are working is beyond the remit of this article, but what is known is that fraudulent insurance claims for motor vehicle accidents continue to be rife with the number of detected claims reaching a value of $£ 800 \mathrm{~m}$ in 2015 (ABI, 2015).

Claims for whiplash, although common, is certainly not the most lucrative injury/disorder to claim for. The average pay-out to those who claim for whiplash here in the UK is estimated to be around $£ 2500$ (Transport Committee, 2013), whereas a claim for psychiatric damages resulting from a RTA can be substantially higher in the region of $£ 82,750$ in severe cases of psychiatric damage (Judical College, 2012). It is being argued that the Government's attempt to reduce fraudulent whiplash claims may be resulting in a rise in the costlier claims for psychiatric damages, a 'displacement effect', possibly explained by accident management companies looking to exploit more profitable conditions (Laws, 2015). Due to the nature of a RTA, the most plausible mental disorder that a claimant may suffer with is Post Traumatic Stress Disorder (PTSD), which is estimated to occur in 15-30\% of RTA collisions (Hall \& Hall, 2006). However, due to the subjective and inexact nature of PTSD symptoms, 


\section{MISSION IMPOSSIBLE?}

researchers have argued that the disorder can be easily fabricated (Hall \& Hall, 2006; 2007; Guriel \& Fremouw, 2003).

Fraudulently claiming illness or injury is referred to in clinical circles as malingering (APA, 2013) this is listed in the DSM-5as a V-code, meaning that malingering is not a mental disorder but is a condition that may be the focus of clinical attention (APA, 2013). In the DSM-5 malingering is defined as the "intentional production of grossly or exaggerated physical or psychological symptoms, motivated by external incentives" (APA, 2013 pp 726). it is suggested to be strongly suspected if any combination of the following occur in clinical presentation:

1. "Medico-legal context of presentation (e.g., the individual is referred by an attorney to the clinician for examination or the individual self refers to while litigation or criminal charges are pending)".

2. "Marked discrepancy between the individual's claimed stress or disability and objective findings and observations".

3. "Lack of cooperation during the diagnostic evaluation and in complying with the prescribed treatment regime".

4. "The presence of antisocial personality disorder".

(APA, 2013, pp 727)

The guidance given to clinicians has been criticised for being characteristic of a criminological model whereby malingerers are regarded as anti-social and bad, which may result in both false positives and false negative diagnoses (Rogers, 1990). It is worth noting that malingering is additionally defined in ICD-10 under the diagnostic code Z76.5 (World Health Organisation, 2017) but the DSM-5 definition is favoured here due to more in depth coverage alongside the rationale that in two previous UK research papers the DSM-5 was 


\section{MISSION IMPOSSIBLE?}

utilised by both a psychologist and psychiatrist practising in the medico legal arena (Cartwright, 2018; Cartwright et al, 2016). The main criticism of the diagnostic criteria afforded by DSM-5 and its predecessors relate to the criteria failing to acknowledge the full breadth of malingering; malingering is not an all or nothing phenomenon (Conroy \& Kwartner, 2006). One of the first academics to write about the different types of malingering did so in 1965 and Garner labelled three sub types of malingering: pure malingering, partial malingering and false imputation (Garner, 1965). Phillip Resnick is, however, often cited for the differing levels of malingering and this is due to Resnick's (1997) work extending the subtypes to the disorder of PTSD. According to Resnick (1997), pure malingering occurs when claimants fabricate non-existent symptoms, partial malingering refers to the claimants who exaggerate real symptoms that they experience, and false imputation refers to the claimant who reports genuine symptoms but knowingly attributes the cause of the symptoms to an event which played no part. Research indicates partial malingering is the most common form (Resnick, 2003; Kleinman \& Stewart, 2004). Having said this, very little is known about the base rates of the three subtypes of malingering as they are yet to be systematically and rigorously studied (Wooley, 2013). Research has however, posited that partial malingering and false imputation are much harder to detect than pure malingering due to the existence of in part genuine symptoms (Hall \& Hall, 2006; Kleinman \& Stewart, 2004).

A review of the reasons and motivations for malingering is not warranted here nor is a full review of the methods for detecting malingering attempted ${ }^{1}$. Identifying malingering is a very difficult task, even for the experienced professional, and the difficulty in detecting malingering can be inhibited by the type of malingering strategy being used (Resnick \& Knoll, 2005; Hall \& Hall, 2006). This is further exacerbated by our ability as humans to

\footnotetext{
${ }^{1}$ Rogers (2008) seminal text is suggested for the interested reader.
} 


\section{MISSION IMPOSSIBLE?}

detect deception. On average, even when testing professional lie catchers, our detection rates are no better than flipping a two-sided coin, with an average accuracy rate gathered from 24 studies of $55.91 \%$ (Vrij, 2008).

Medico legal clinicians have a limited number of methodologies for detecting malingering and these are as follows: through the examination of collateral evidence, clinical interviewing employing clinical judgment, and/or using psychometric assessments. Blanchard and Hickling's (2004) research illustrates the difficulty of detecting malingering through clinical judgment. Blanchard and Hickling (2004) introduced six trained actors into a research project investigating the psychological effects of RTAs and found substantially different detection rates when the psychologists were primed to search for the actors in their case files after the actors had initially been undetected. Such findings cast doubt on clinicians' ability to detect malingering unaided.

Rogers (2008) suggests that the use of structured assessments present the clinician with an efficient methodology for screening for malingering. Indeed, there are several psychometric instruments that have validity measures designed to detect malingering but testing their ability to detect malingering is problematic based on the difficulties with establishing the ground truth. Such assessments that have specific capabilities to detect feigned mental disorder are as follows: the M-FAST (Miller, 2001), the Personality Assessment Inventory (PAI; Morey, 1991), the Minnesota Multiphasic Personality Inventory-2 (MMPI- 2, Butcher, Dahlstrom, Graham, Tellegen, \& Kaemmer, 1989), and the Structured Interview of Reported Symptoms (SIRS-2; Rogers, Sewell \& Gillard, 2010). Such instruments do have empirical support for their ability to detect malingering (e.g. Vitacco et al., 2008; Hawes \& Boccaccini, 2009; Iverson and Lange, 2006; Liu et al., 2013). In a review of a sample of American 


\section{MISSION IMPOSSIBLE?}

forensic practitioners, the MMPi-2 and the SIRS were suggested to be the most effective instruments for the detection of malingering (Lally, 2003).

At the time of writing, no reviews have explored whether such assessments are used within UK practice, however, a handful of studies originating from North America and Australia have explored the use of psychometrics assessments. Slick (2004) surveyed practising medico-legal neuropsychologists $(N=24)$ in North America and found considerable variations in the use of symptom validity assessments employed by the professionals. The results suggested that the choice of test used by professionals was questionable considering that the second most frequently used test had been proven to be poor in terms of sensitivity to detecting malingering. Slick's (2004) research additionally evidenced that the professionals' perceptions of the base rates of malingering differed but the average confidence rating of their ability to detect malingering was 7.75 out of 10 ; thus suggesting they were in general very confident in their ability to detect malingering. Having said this, it was evidenced that only $37.5 \%$ of professionals warn their claimants regarding malingering (Slick, 2004) despite research which advocates the use of a structured warning (King \& Sullivan, 2009). A similar study conducted by Sharland and Gfeller (2007) provided the same outcome with a larger sample of practising neuropsychologists $(N=188)$. Sharland and Gfeller (2007) revealed that only $22 \%$ of their participants always provided a warning to claimants prior to evaluation, with $56 \%$ stating that they never provide a warning. Furthermore, the use of tools to detect malingering within neuropsychological assessment differed substantially and in support of Slick and colleagues (2004) findings, neuropsychologists continued to employ certain assessments despite a lack of empirical support in the literature (Sharland \& Gfeller, 2007).

In a more recent study, Yoxall, Bahr and Barling (2010) surveyed practising medico-legal psychologists $(\mathrm{N}=102)$ in Australia and explored their views on detecting malingering. The 


\section{MISSION IMPOSSIBLE?}

results provided a worrying insight, for example, with nearly one quarter of professionals stating that malingering had not occurred in their assessments within the past year.

Furthermore, the estimated base rate of malingering in medico-legal contexts was estimated to be between $5 \%$ to $10 \%$. The use of specialised malingering assessment tools were not consistently or routinely used by psychologists (Yoxall, Bahr \& Barling, 2010). It was also reported that only $26 \%$ of professionals routinely warned participants about malingering prior to evaluation and there was no consensus between psychologists regarding the cause of malingering. (Yoxall, Bahr \& Barling, 2010). Yoxall and colleagues' findings led them to conclude that it is often unclear what professionals are relying upon to detect deception, should they not implement appropriate instruments (Yoxall, Bahr \& Barling, 2010). Such inconsistencies regarding the use of psychometrics is not uncommon. Neal and Grisso (2014) explored 494 practitioners' assessment methods and revealed that there were a staggering 286 different tools being used in forensic practice. However, when broken down into a specific type of assessment there were 42 different assessment tools being used across civil tort referrals, under which RTA personal injury claims would fall (Neal \& Grisso, 2014).

Until recently very few research articles have explored assessments of mental disorder in the UK civil litigation arena. In a brief case study of one psychiatrist's portfolio of RTA medico legal claimants $(N=100)$ it was found by (Cartwright et al, 2016) that up to $40 \%$ of claimants' declared mental disorder could be classified as not being attributable to the RTA. In a different study, Cartwright (2018) reviewed a larger sample of RTA claimants (N=305) originating from one psychologist's career of RTA assessments and when the two examiners' methodologies were compared, substantial differences were observed. In both studies the medico-legal examiners did not warn their claimants. Having said this, psychometric assessments were used in both studies but only the psychiatrist in Cartwright and colleagues' 


\section{MISSION IMPOSSIBLE?}

(2016) article used a psychometric tool with a validity indicator, whereas in Cartwright's (2018) paper the psychometric assessments that were employed were seriously questioned by the researcher. Additionally, the psychologist in Cartwright's (2018) article did interview a friend or family member to corroborate the claimant's attested mental disorder. But it is unknown whether this is common practice within UK medico-legal assessors.

Considerable differences emerge within the assessment of RTA claimants in the UK through the comparison of two professionals but it is not possible to generalise such differences without further research. Having said this, such idiosyncrasies have been noted in both Australia (Yoxall, Bahr \& Barling, 2010) and North America (Sharland \& Gfeller, 2007) and therefore it is important that such research is conducted in the UK with the wider community of medico-legal assessors. Such inconsistencies that have been noted in previous research are certainly worrying and this is exacerbated when one considers the recent findings of Cartwright and Roach's (2016) study that provides evidence that the UK public, in general, do not perceive the malingering of mental disorder following a RTA to be considered serious. In line with Rogers' (1990) adaptational model of malingering, it is argued here that should individuals perceive malingering not to be serious then they may be more inclined to malinger should a suitable opportunity arise. As a result, the present article aims to provide an original and rigorous exploration of how medico-legal assessments in the UK are conducted focusing specifically on RTA assessments where deception may be of concern.

\section{Method}

\section{Participants}

The number of professionals who conduct assessments for mental disorder within the medico-legal arena in the UK is indiscernible, therefore, the study utilised a purposive 


\section{MISSION IMPOSSIBLE?}

sampling technique. Four expert witness databases and the British Psychological Society agreed to help advertise the study to their members. An advert was placed in the British Psychological Society's monthly magazine and an email was sent to each member of the four expert witness databases. A total of 37 participants agreed to take part in the present study, however, towards the end of the survey several participants left and did not return meaning that the lowest number of participants in any given analysis was 32 .

It is important to acknowledge that the number of participants may be viewed as low by readers based in the United States and similar countries where the healthcare system is vastly different to here in the UK. However, assessments for mental disorder within civil litigation in the UK are undertaken outside of the National Health Service, where most Psychiatrists and Psychologists practice. As a result, the number of professionals who conduct such assessments will be considerably lower when compared to professionals operating within different countries as it is simply not part of their routine practice. As a result, the sample size used within the present study is argued to be representative of the minority of professionals who undertake specific assessments of mental disorder following RTAs in the UK. Detailed in table one are the participants' professional demographic information.

\section{[TABLE ONE HERE]}

\section{Procedure}

An online qualitative survey (Janson, 2007) was used within the present article, participants were required to answer a maximum of 52 questions but the level of detail required for each differed, for example some questions invited a detailed qualitative response whereas others only required a brief phrase or a numeric response. The development of the questions included in this survey derived from the findings of two previous quantitative research 


\section{MISSION IMPOSSIBLE?}

articles, which were conducted by members of the research team (Cartwright et al, 2016; Cartwright, 2018). The two previous studies (as outlined in the introduction) evidenced substantial methodological inconsistencies and weaknesses between two UK assessors and as a result, the questions in the present study aimed to explore these issues with the wider medico-legal community. The Qualtrics online research suite was utilised to host the survey.

\section{Analysis}

The use of qualitative description was chosen as the most appropriate methodology (Sandelowski, 2001). Qualitative description as a methodology is a useful framework for the analysis of qualitative data where the researcher wishes to explore the data without making inferences (Sandelowski, 2000). As opposed to methods such as grounded theory or phenomenological research qualitative description is low in inference and does not look to probe for underlying meaning within data. Rather this method of qualitative research is concerned with presenting the findings in "everyday language" (Sandelowski, 2000 pp 336). A directed content analysis procedure was utilised whereby the participants' answers were coded and recorded for each question of the survey. For the survey questions which required a closed response or a single word/ phrase answer these were recorded quantitatively. Concerning the more detailed qualitative responses, codes were generated and recorded for each question to describe the data. Descriptive statistics were used to describe the data using IBM SPSS.

\section{Ethics}

The present study was designed in accordance with the British Psychological Society's code of human research ethics and was approved by the University of Huddersfield's School of Social and Health Sciences research ethics panel. 


\section{Results}

\section{The Medico-Legal Process}

The first area of focus was the medico-legal process, participants were first asked who instructs their medico legal assessments: $56 \%$ said that they receive their referrals through both solicitors and agencies ${ }^{2}, 28 \%$ through only solicitors, $10 \%$ through only agencies, and $5 \%$ of participants' responses were not clear $(\mathrm{N}=37)$. Participants were then asked to estimate from their experience the typical length of time between the initial accident and their examination of the claimant. The mean time between the RTA and evaluation as reported by 34 participants based on their experience was 18.4 months ranging from 6 months to 39 months.

A second question asked what happens after the medico legal report has been written; participants were asked about the frequency in which they follow a claimant's case through to court to find out about the outcome of the case. The analysis was based upon 36 professionals as one professional's response was unclear. $5.6 \%(n=2)$ indicated that they always follow a claimant's case through to court, $5.6 \%(n=2)$ indicated that they follow $75 \%$ of their cases through to court, $2.8 \%(n=1)$ estimated that they obtain the outcome of the case in roughly $50 \%$ of cases, $2.8 \%(n=1)$ estimated that they are made aware of the outcome of $25 \%$ of their cases, 58.3\% ( $n=21)$ indicated that they rarely get feedback, and 25\% (n=9) highlighted that they have never followed a case through to court to obtain the outcome or have never been told the outcome by the instructing party.

\footnotetext{
${ }^{2}$ For the reader who is unsure what is meant by the term agency as used above, an agency is company who essentially play the 'middle man' and provide solicitors with medico-legal examiners for a fee. Whereas direct referrals from solicitors will not involve a fee and the entire payment will go to the medico-legal examiner, although the examiner would indeed need to advertise their services through an expert witness database to receive referrals.
} 
MISSION IMPOSSIBLE?

\section{Evidence utilised}

To gain an understanding of what forms of evidence UK assessors typically use the participants were asked to detail these. The findings of the content analysis revealed that medical records are highly important in the assessment of medico-legal claimants, $62.2 \%$ $(n=23)$ of participants indicated that they accessed all claimants' medical and mental health records, suggesting that not all clinicians are able to use medical records in their assessments'. $35.1 \%(n=13)$ of participants indicated that they attempt to access every claimant's previous medical/mental health records but reported that sometimes it is not possible. $2.7 \%(n=1)$ indicated that they only accessed medical/ mental health records in certain circumstances. For those who indicated that it is not always possible to obtain medical records stated several reasons for why this is the case including: time restrictions, instructed to complete a report without access, and medical records not being available for low value claims.

Participants were asked if they access a claimant's criminal records. One participant's response was excluded from this stage of the analysis due to inconsistency in their response. $36.1 \%(n=13)$ of participants stated that they do not attempt to access claimants' criminal records, $11.1 \%(n=4)$ access every claimants' criminal records, $8.3 \%(n=3)$ attempt to access every claimants' criminal records but sometimes cannot gain access, and $44.5 \%(n=16)$ only access claimants' criminal records under certain circumstances. When participants were asked under what circumstances they would access criminal records in RTA evaluations it became clear that in general participants perceived checking criminal records to be irrelevant in the current context. 


\section{MISSION IMPOSSIBLE?}

Detailed in table two are the other forms of evidence that participants reported being sent from instructing parties. It is evident that from table two there exists inconsistencies in what is sent to the professional in RTA cases. This notion of inconsistent evidence is further supported by table three which includes extracts from the participants.

\section{[TABLE THREE HERE]}

\section{Psychometric Assessments}

Participants were asked about their use of psychometric assessment tools, 68\% $(n=25)$ of the sample stated that they used at least one tool in their assessment methodology, and $32 \%$ $(n=12)$ indicated that they do not use psychometric assessments at all. Of those who did employ a psychometric tool $8 \%(n=2)$ employed just one; $20 \%(n=5)$ employed two, $36 \%$ $(n=9)$ employed three; $16 \%(n=4)$ employed four tools; $4 \%(n=1)$ employed five tools and 4\% $(n=1)$ employed seven tools. $12 \%(n=3)$ of participants who employed psychometric testing indicated that they use a variety of assessments but chose not to specify the number of tools that they typically employed.

\section{[TABLE FOUR HERE]}

As can be seen in table four a total of 32 assessments tools were listed by 25 participants, demonstrating little consistency in the tools used. Each individual psychometric assessment was examined; only three assessment tools used included validity scales and these tools were only implemented by five professionals meaning that only $20 \%(n=5)$ of those professionals who employ psychometrics assessments utilise an appropriate tool that has the capability of indicating exaggeration. Furthermore, when examining only the psychometric assessment tools that have been designed to specifically measure malingering, this number drops to $8 \%$ $(n=2)$ of participants who employ psychometric assessments utilising an assessment which 


\section{MISSION IMPOSSIBLE?}

has the specific capability of identifying malingering with the two assessments being the Minnesota Multiphasic Personality Inventory Two and the Paulhus Deception Scale.

A further area of analysis regarding the professionals' psychometric tests was whether the assessments were easily accessible online, 'easily accessible' can be defined as whether the physical assessment tool can be accessed through a simple Google search. Consequently, the researcher completed this search for the psychometric assessments listed in table seven limiting the search field to the first two pages listed on Google. As can be seen in table seven the findings of this analysis evidenced that $77 \%(n=24)$ of the reported psychometric assessment tools were accessible online with a full list of questions. Finally, as can be seen in table seven, the average age of the assessments in use (at the time of publication) is 23 years old and this is an important consideration when one considers that the DSM has undergone a total of three revisions in this period.

\section{Professionals' Assessment Methodologies}

To understand the extent to which the overall methods of assessment in the UK differ from professional to professional, it was considered important to ask those working in the arena to describe their assessment process. Participants were simply asked: In as much detail as you can, please describe your routine assessment as accurately as possible. Please include all the evidence that you typically request or collect and please write your answer in the order in which your assessment is undertaken from referral to completed report. Participants' responses were analysed and three categories relating to the differing assessment processes emerged which was consistent across the three researchers. The three categories identified were labelled by as follows: The evidence interview approach; the three-stage approach; and the corroborative two to three stage approach. 
MISSION IMPOSSIBLE?

\section{The evidence interview approach: category one.}

This approach consists of the professional examining various forms of evidence and conducting an interview with the claimant. It must be noted that the forms of evidence utilised differ greatly between professionals, although the findings of this initial analysis evidence that, those professionals who employ this methodology, typically examine general practitioner notes, hospital records, any psychiatric/psychological records, and any evidence that is sent through from the instructing party. The professional will then use this information within an interview with the claimant to complete the report that has been requested by the instructing party. It is important to note that what constitutes an interview differs significantly between professionals and this will be explored in more detail. Detailed in table five are qualitative extracts to provide evidence of this approach.

\section{[TABLE FIVE HERE]}

\section{The three-stage approach: category two}

The second distinct method of assessment that was found was categorised as the three-stage approach; the way in which this type of assessment is different to the evidence interview approach described previously is because the professionals utilising this approach indicated that on top of reviewing evidence and conducting an interview the professional also employed the use of psychometric testing. Again, it is important to note that the use of psychometric testing employed by professionals differs substantially and this is something that will be examined. Detailed in table six is a qualitative demonstration of the three-stage approach.

\{TABLE SIX HERE]

The corroborative (two to three stage) approach: category three 


\section{MISSION IMPOSSIBLE?}

The third distinct type of methodology that was revealed was labelled the corroborative (Two to Three Stage) approach; this assessment category shares similarities with the previous two methodologies. However, the professional utilising this approach additionally seeks to interview a member of family or a close friend of the claimant. Consequently, the corroborative methodology adds a further level of assessment to the previous methodologies that have been identified. Again, it is also worth noting that there are subtle differences between the participants' responses with some professionals indicating that that they always speak with a family member and others indicating only if available. Nonetheless, this is a further layer to the assessment process, which separates the participants' description of their assessment processes into three distinct methodologies. Table seven evidences the qualitative demonstration of the corroborative approach.

\section{[TABLE SEVEN HERE]}

\section{Malingering}

Participants were asked to estimate the prevalence of malingering within their practice (specifically to RTA assessments) and the mean estimation of the extent to which malingering occurs in the participants' experience was reported as 9.9\% $(M=9.9, S D=10.3)$. It is apparent that the professionals within the present study estimate that malingering occurs relatively infrequently and several participants indicated that they were not able to estimate the extent to which malingering occurs within their examinations; two participants commented that they are not able to assess malingering in the present arena and this is of concern.

The survey examined participants' knowledge of the three malingering strategies, participants were asked whether they were familiar with the three strategies of malingering. $55.6 \%(n=20)$ 


\section{MISSION IMPOSSIBLE?}

were familiar with the three malingering strategies, thus meaning that $44.4 \%(n=16)$ of participants were not familiar with pure malingering, partial malingering and false imputation. Participants were provided with information regarding the three malingering strategies and then asked to estimate the prevalence of these occurring within their practice. The mean estimation of pure malingering was the lowest approximation at 1.6\% $(M=1.6$, $S D=2.2, n=29)$ followed by partial malingering at $6.8 \%(M=6.7, S D=8.7, n=27)$ and then false imputation at $9.4 \%(M=9.4, S D=8.7, n=29)$.

A further area of interest was whether participants warn claimants about exaggerating symptoms. It was revealed that the over whelming majority of participants do not warn claimants about exaggerating symptoms with $87.5 \%(n=28)$ stating that they have never done this, leaving only $12.5 \%(n=4)$ of participants who stated they routinely do this. Participants were then asked what they believe to be the most indicative factors of malingering which they utilise within their practice. Participants responses are detailed in table eight. Participants were further questioned about how they specifically detect false imputation. Participants listed several ways but the most consistent response which was given 22 times was through utilising medical records.

\section{[TABLE EIGHT HERE]}

\section{Further issues identified}

Several issues were identified by the participants within the present study, one concern that emerged was the lack of specific training within this area of medico legal practice, several training events were listed by participants but upon review of the training events very few 


\section{MISSION IMPOSSIBLE?}

were specific to this arena and even fewer were focused upon the detection of malingering.

Several participants also shared their concerns' regarding the quality of the reports that are created in this arena and detailed below are extracts that demonstrate this:

Experts “... should stop just transcribing their over long interviews, stop using invalid psychometrics and always consider impartially previous function and medical evidence. Psychologists in particular should stop churning out tick box reports wholly dependent upon self-report. Experts should stop routine overcharging for what in many cases is a basic assessment interview without any objective evidence being considered." (P29).

"The ridiculous situation when solicitors ask for a percentage attribution of causation needs to be addressed - I always refuse to do this, unless it is v clear that the index event is entirely the cause. In complex cases it is impossible but I know colleagues who do this and to be frank I think it is just made up" (P31).

"I have stopped doing these reports now since I find them so unsatisfactory. I think there is evidence of some doctors and psychologists being over-willing to suspend disbelief or to over-use pseudo-objective rating scales to create pseudo-disorders" (P38).

\section{Discussion}

To the authors' knowledge this is the first study that has undertaken an exploratory analysis of the assessment of mental disorder in the personal injury arena in the UK. The first finding to be discussed is the overwhelming lack of consistency between experts in the UK who are conducting assessments for mental disorder following a RTA. The lack of consistency was observed in many situations, for example, the amount of psychometric assessment tools $(N=32)$ in use, the differing forms of evidence utilised by the professionals, and the differing approaches to the clinical interview. Even though three broad types of assessment emerged, some of the intricate components of the assessment methods substantially varied. Due to the vast differences found here, granted with some professionals implementing methodologies supported by research albeit if only a few, it is posited that it is unlikely that there would be an acceptable level of consistency in diagnoses due to the idiosyncratic assessment methods 


\section{MISSION IMPOSSIBLE?}

evidenced. This is something that has been found in previous international studies (e.g. Neal \& Grisso, 2014; Yoxall, Bahr \& Barling, 2010), however, the present study now provides evidence of such inconsistencies within UK practice also.

A further finding to discuss is the timing of the assessments, based on the experiences of the clinicians involved in the present study the average time between the initial accident and assessment stands at around 18 months. Heron-Delaney, Kenardy, Charlton and Matsouka (2013) studied the onset of PTSD following RTAs at different intervals. The results of their systematic review revealed that at one month, PTSD prevalence was estimated to be between $8 \%$ to $45 \%$ of survivors, at three months $8-30 \%$, at six months $6-28 \%$, and at twelve months 7-26\% (Heron-Delaney et al., 2013). Heron-Delaney and colleagues (2013) suggest that over time the prevalence of PTSD decreases and attribute this to the remission of PTSD symptoms. Therefore, based on Heron-Delaney and colleagues' (2013) work that earlier assessments may be beneficial to ensure that those who do suffer with PTSD can be identified prior to their symptoms going into remission. Furthermore, it may be the case that 18 months is too long due to the possibility of many events occurring within a claimant's life between the date of the RTA and the date of the evaluation. As a result, it is suggested that the time between the RTA and evaluation is potentially problematic and is something that should be the focus of further academic, practitioner, and policy discussions.

It was found that $83.8 \%$ examiners either never or rarely are told the outcome of the cases that they assess. This is something that the present article deems important as the reduction of cognitive biases is directly dependent upon frequent feedback (Dawes, 1989) which most UK medico-legal examiners simply do not receive. 


\section{MISSION IMPOSSIBLE?}

The next area of discussion is in relation to participants' practices regarding detecting malingering. The findings of the present study do raise the question that it is unclear how professionals consider malingering. This is evidenced through the finding that only three psychometric assessments were employed that have dedicated validity indicators for detecting malingering. As for the three professionals who used psychometric assessments with validly scales, only one professional utilised what academic literature would suggest being suitable in the present arena (Cartwright, 2018a). The MMPI-2 was only used by one professional included in the present article with no professionals employing the assessments that have been suggested as effective tools specifically for the detection of malingering: e.g. the M-Fast (Miller, 2001) and the SIRS-2 (Rogers, Sewell \& Gillard, 2010). As a result, the findings reported here would suggest that UK medico- legal assessors do not consider malingering to be important and this is something that certainly should be discussed and addressed by future research.

When considering the findings of research investigating detecting deception it is clear that deception is difficult to detect (e.g. DePaulo et al., 2003; Vrij, 2008) and when such findings are combined with evidence of inaccuracies in psychological assessment (e.g. Rosen, 1995; Blanchard \& Hickling, 2004), this suggests a potential recipe for disaster, with malingered claims for mental disorder potentially going undetected due to a lack of consideration. An analysis of the tools that are indeed used by professionals provides some concern with many assessments employed being fully accessible online. Consequently, it is crucial that professionals gain a better understanding of the suitability of their assessment as it is argued here that using psychometric assessments that are accessible online might not be appropriate given the context of the evaluation. This is of further concern when the results of a seminal study evidence that $48 \%$ of attorneys and $33 \%$ of law students believe claimants should be 


\section{MISSION IMPOSSIBLE?}

told about the psychological assessments to be used by medico-legal professionals (Wetter \& Corrigan, 1995).

Previous research has evidenced that preventing malingering can be successful using a warning grounded in deterrence theory (King \& Sullivan, 2009) and the results of previous research by Cartwright and Roach (2016) investigating the public perception of the severity of malingering certainly advocates the need for the use of a warning. However, the results of the present study outline that the majority $(87.5 \%)$ of examiners do not implement such warnings within their practice.

In the situation where a claimant already has a mental disorder but states that the RTA which they have been involved in is to blame, it is thought to be the most difficult to detect. The reason for this is that claimants are in fact reporting genuine symptoms but their origin is the part of the claim that is deceitful. Notably, medico-legal examiners were asked how they go about determining that this is not the case in their evaluations. The consensus was that a detailed clinical interview alongside a thorough examination of collateral evidence, mainly medical records, is the only way to do this. Conversely, several medico-legal professionals (36\%) reported that they sometimes conduct assessments without medical records because they are difficult to obtain. This finding is a further cause for concern as it evidences that roughly a third of medico-legal examinations are extremely vulnerable to claimants malingering utilising a false imputation strategy.

The significance of this finding is further put in to context when the findings of Cartwright's (2018) article based on the psychometric data of RTA claimants' evidences that $45 \%$ $(N=138)$ of those who were referred to one medico legal psychologist had some level of 


\section{MISSION IMPOSSIBLE?}

previous mental disorder. This is particularly concerning considering the difficulties that some examiners face when requesting medical records. Put simply, the chance of a claimant having a previous mental disorder is particularly high and thus this would allow a claimant to utilise a false imputation strategy. Alongside previous psychiatric history the results revealed in Cartwright's (2018) study, that $30 \%$ of the claimants had experienced some form of significant life event between the RTA and the psychologist's assessment. In addition, the extent to which claimants had experienced a significant life event positively correlated with the psychometric assessment scores (Cartwright, 2018). Subsequently, demonstrating that should medical records be left unchecked, it is improbable that a medico-legal professional could rule out that such life events were not attributable to the claimant's current mental disorder without relying on self-reported admissions attested during the clinical interview.

To thoroughly reiterate the points raised within this part of the discussion, it is important to consider a final finding in relation to the detection of malingered mental disorder. It was evidenced that $44 \%$ of professionals involved in the present study were not familiar with the three differing types of malingering by name. This suggests that there is a clear issue regarding a lack of accurate knowledge concerning malingering and, taken alongside the other findings discussed thus far, evidences that the assessment of mental disorder claims following a RTA in their present form might not be adequate.

Although, malingering is a topic of concern for medico-legal examiners which should be considered within assessments, the final decision as to whether a claimant has malingered is determined by the courts through several forms of evidence including the report submitted by the medico- legal assessor. Notably, the value of this research is to offer an insight into the ways in which medico-legal examiners may improve the evidence included within their 


\section{MISSION IMPOSSIBLE?}

reports, which are submitted to the courts. It is important to clearly state that there does not exists a tool that can clearly identify malingerers, nor does the present article wish to state that medico-legal examiners must use a psychometric assessment. The argument presented here is that medicolegal reports may prove to be of further evidential use to the courts should assessments consider malingering.

The implications of this article's findings for individual medico-legal examiners are varied, and it is not anticipated or expected that examiners will make changes to their assessment based on this article alone. At this stage and in the interim period between the findings of this article and future research and/or action, the message to examiners is relatively succinct. Examiners should consider the methods that they are implementing to assess claimants' mental disorder and assess whether any of the limitations identified within this article are relevant to their practice. It is suggested here that the following points might be useful guidelines to follow to ensure that the final medico-legal report provides sufficient evidence to the court to assist with the determination of malingering:

1. Appropriate psychometric assessments might be useful to incorporate to support additional existing assessment methodologies such as the clinical interview.

2. Where possible a corroborative interview should be undertaken to support additional assessment methodologies.

3. Assessments should only commence once full access to medical records has been provided.

4. The assessment should consider the possibility of malingering occurring.

5. Assessors should attempt to seek feedback regarding the outcome of each case. 


\section{MISSION IMPOSSIBLE?}

A suggested way forward in the improvement of medico-legal assessments for mental disorder in this arena is the development of a governing body which can regulate and quality assure the work of practitioners. A regulating body that overlooks the entirety of the medicolegal process is argued to be the most effective way of reducing the issues that this article has flagged as important. Such governing body could ensure consistency with regards to the instruction and evidence sent to clinicians, the assessment methods employed by clinicians, and the feedback given to clinicians.

Finally, it is important to acknowledge the limitations of this study. As a non-random sampling method was used in the recruitment of participants, it should be recognised that this might have resulted in a bias sample of professionals taking part. In addition, the size of the population under study is unknown as there is no information accessible on how many professionals are conducting such assessments for RTA claimants. Consequently, it is important to note that the sample size utilised in this paper may not be representative.

\section{Conclusion}

In summary, the present article has identified a variety of issues that have arisen from an analysis of UK medico legal assessment methodologies for mental disorder following RTAs. It should be reiterated that this article does not wish to suggest that examiners should be blamed for the inconsistent practice revealed within this study. A lack of applied research, training, and regulation is accountable for many of the issues highlighted within this article. In summary, it is hoped that this article offers a platform to encourage researchers to address some of the limitations alluded to here, whilst opening a constructive discussion on how academics, practitioners, and policy professionals can work together to improve this area of medico-legal practice. 


\section{References}

American Psychiatric Association. (2013). Diagnostic and statistical manual of mental disorders (5th ed.). Washington, DC: Author.

Association of British Insurers. (2012). No Hiding Place. Retrieved January 2016 from: https://www.abi.org.uk/ /media/Files/Documents/Publications/Public/Migrated/Fraud /ABI\%20no\%20hiding\%20place\%20-\%20insurance\%20fraud\%20exposed.pdf

Association of British Insurers. (2015). You could not make it up, but they did. Savings for honest customers as insurers expose $£ 3.6$ million worth of insurance frauds every day. Retrieved January 2016 from: https://www.abi.org.uk/News/Newsreleases/2015/07/You-could-not-make-up-Savings-honest-customers-insurers-expose3-6-million-worth-insurance-frauds

Association of British Insurers. (2014). Insurance cheats feel the heat - value of fraudulent claims uncovered by insurers hits record level. Retrieved January 2016 from: https://www.abi.org.uk/News/News-releases/2014/05/Insurance-cheats-feel-the-heatvalue-of-fraudulent-claims-uncovered-by-insurers-hits-record-level

Blanchard, E. B., \& Hickling, E. J. (2004). Can you detect malingered MVA-related PTSD? The Albany MVA project's answer (2nd ed.). Washington DC: American Psychological Association.

Butcher, J. N., Dahlstrom, W. G., Graham, J. R., Tellegen, A., \& Kaemmer, B. (1989). Minnesota Multiphasic Personality Inventory-2 (MMPI-2): Manual for administration and scoring. Minneapolis, MN: University of Minnesota Press.

Cartwright, A. \& Roach, J. (2016). Fraudulently claiming following a RTA: A pilot study of UK residents' perceptions. Psychiatry, Psychology and Law, 23 (3), 446-461. DOI:10.1080/13218719.2015.1080148

Cartwright, A., Roach, J., Wood, H., \& Wood, P. (2016a). Malingering and the fraudulent motor insurance claimant. Open Access Journal of Forensic Psychology, 8, 1- 16. ISSN 1948-5115.

Cartwright, A. (2018) The Psychological Effects of Road Traffic Accidents: An Exploration of a UK Medico Legal Examiner's Career of RTA Assessments. Psychiatry, Psychology and Law,25 (2), 303-324. DOI:10.1080/13218719.2017.1396864

Cartwright, A. (2018a). May the choice be with you: The use of psychometric assessment tools in personal injury evaluations. Manuscript submitted for publication.

Conroy, M. A. \& Kwartner, P. P. (2006). Malingering. Applied Psychology in Criminal Justice, 2(3), 29-51.

Criminal Justice and Courts Act (2015). Retrieved January 2016, from http://www.legislation.gov.uk/. 
DePaulo, B., Lindsay, J., Malone, B., Muhlenbruck, L., Charlton, K., \& Cooper, H. (2003). Cues to deception. Psychological Bulletin, 129(1), 74-112. http://dx.doi.org/10.1037//0033-2909.129.1.74

Garner, H. (1965). Malingering. Illinois Medical Journal, 128, 318-319.

Grayling, C. (2014). Keynote Speech by the Secretary of State for Justice. ABI Motor Conference December 2014. Transcript retrieved from: https://www.abi.org.uk/News/Speeches/2014/12/Chris-Grayling-speech-at-the-ABIMotor-Conference-2014.

Hall, R. C. W., \& Hall, R. C. W. (2006). Malingering of PTSD: Forensic and diagnostic considerations, characteristics of malingerers and clinical presentations. General Hospital Psychiatry, 28, 525 - 535. doi:10.1016/j.genhosppsych.2006.08.011.

Hawes, S., \& Boccaccini, M. (2009). Detection of overreporting of psychopathology on the Per- sonality Assessment Inventory: A meta-analytic review. Psychological Assessment, 21(1), 112-124. http://dx.doi.org/10.1037/a0015036

Heron-Delaney, M., Kenardy, J., Charlton, E., \& Matsuoka, Y. (2013). A systematic review of predictors of posttraumatic stress disorder (PTSD) for adult road traffic crash survivors. Injury, 44(11), 1413-1422. http://dx.doi.org/10.1016/j.injury.2013.07.011

Iverson, G., \& Lange, R. T. (2006). Detecting exaggeration and malingering in psychological injury claims. In W. J. Koch, K. S. Douglas, T. L. Nichols \& M. L. O'Neill (Eds.), Psychological Injuries: Forensic Assessment, Treatment, and Law (pp. 76-112). New York, NY: Oxford University Press.

Jansen, H. The Logic of Qualitative Survey Research and its Position in the Field of Social Research Methods. Forum Qualitative Sozialforschung / Forum: Qualitative Social Research, [S.1.], v. 11, n. 2, mar. 2010. ISSN 1438-5627.

Judicial College. (2013). Guidelines for the assessment of general damages in personal injury cases.

King, J., \& Sullivan, K. (2009). Deterring malingered psychopathology: The effect of warning simulating malingerers. Behavioral Sciences \& The Law, 27(1), 35-49. http://dx.doi.org/10.1002/bs1.839

Kleinman S., \& Stewart L. (2004). Psychiatric-legal considerations in providing mental health assistance to disaster survivors. Psychiatric Clinics of North America, 27 (3), 559-570. doi:10.1016/j.psc.2004.03.008.

Lally, S. J. (2003). What tests are acceptable for use in forensic evaluations? A survey of experts. Professional Psychology: Research and Practice, 34(5), 491-498. doi:10.1037/0735-7028.34.5.491 
Laws, A. (2015). Fit for purpose or a MRO (Medical Reporting Omnishambles)?. Carter Law. Retrieved January 2016 from: http://www.carterlaw.co.uk/medco-is-it-fit-forpurpose/.

Levinson, P. (1990). Computer conferencing in the context of the evolution of media. In Harasim, L.M. (ed.), Online education: perspectives on a new environment. NY: Praeger.

Liu, C., Liu, Z., Chiu, H., Carl, T., Zhang, H., \& Wang, P. et al. (2013). Detection of malingering: psychometric evaluation of the Chinese version of the structured interview of reported symptoms-2. BMC Psychiatry, 13(1). http://dx.doi.org/10.1186/1471-244x-13-254

MedCo. (2015). Retrieved March 2015, from: http://www.medco.org.uk/home/.

Merten, T., Dandachi-FitzGerald, B., Hall, V., Schmandd, B., Santamaríae, P., \& GonzálezOrdi, H. (2013). Symptom validity assessment in European countries: Development and state of the art. Clínica Y Salud, 24(3), 129-138. http://dx.doi.org/10.1016/s11305274(13)70014-8.

Miller, H.A. (2001). Miller-Forensic Assessment of Symptoms Test (M-FAST): Professional manual. Odessa, Fl: Psychological Assessment Resources.

Murray, C., \& Sixsmith, J. (1998). E-mail: a qualitative research medium for interviewing? International Journal of Social Research Methodology, 1(2), 103-121. http://dx.doi.org/10.1080/13645579.1998.10846867

Morey, L. C. (1991). Personality Assessment Inventory: Professional Manual. Odessa, FL: Psychological Assessment Resources.

Neal, T., \& Grisso, T. (2014). Assessment practices and expert judgment methods in forensic psychology and psychiatry: An International Snapshot. Criminal Justice and Behavior, online first publication September 25, 2014. doi:10.1177/00093854814548449.

Resnick, P. (1977). Malingering of posttraumatic disorders. In: Rogers R, editor. Clinical assessment of malingering and deception (pp 130 - 52) (3rd ed,). New York, Guilford Press.

Resnick, P. J., \& Knoll, J. L. (2005). Faking it: How to detect malingered psychosis. Current Psychiatry, 4, 13-25.

Rogers, R. (1990). Development of a new classificatory model of malingering. Bulletin of the American Academy of Psychiatry and Law, 18, 323-333.

Rogers, R. (2008) Clinical assessment of malingering and deception (3rd ed.). New York, Guilford Press. 
Rogers R, Sewell KW, Gillard ND (Eds): Structured Interview of Reported Symptoms-2 (SIRS- 2) and Professional Manual. Odessa, FL: Psychological Assessment Resources; 2010:76-77.

Rosen, G. (1995). The Aleutian Enterprise sinking and posttraumatic stress disorder: Misdiagnosis in clinical and forensic settings. Professional Psychology: Research and Practice, 26(1), 82-87. http://dx.doi.org/10.1037//0735-7028.26.1.82

Rosenhan, D. (1973). On Being Sane in Insane Places. Science, 179(4070), 250-258. http://dx.doi.org/10.1126/science.179.4070.250

Sandelowski, M. (2000). Whatever happened to qualitative description?. Res. Nurs. Health, 23(4), 334-340. http://dx.doi.org/10.1002/1098-240x(200008)23:4<334::aidnur9>3.0.co;2-g

Sharland, M. \& Gfeller, J. (2007). A survey of neuropsychologists' beliefs and practices with respect to the assessment of effort. Archives of Clinical Neuropsychology, 22(2), 213223. http://dx.doi.org/10.1016/j.acn.2006.12.004

Slick, D. (2004). Detecting malingering: a survey of experts? practices. Archives of Clinical Neuropsychology, 19(4), 465-473. http://dx.doi.org/10.1016/s0887-6177(03)00112-4

Transport Committee (2013). Cost of motor insurance: whiplash. Retrieved November 2013 from:http://www.publications.parliament.uk/pa/cm201314/cmselect/cmtra n/117/11704.htm.

Vitacco, M. J., Jackson, R. L., Rogers, R., Neumann, C. S., Miller, H. A., \& Gabel, J. (2008). Detection strategies for malingering with the Miller Forensic Assessment of Symptoms Test - A confirmatory factor analysis of its underlying dimensions. Assessment, 15(1),97-103

Vrij, A. (2008). Detecting Lies and Deceit, pitfalls and opportunities (2nd Ed.). John Wiley and Sons, Chichester, UK.

Wetter, M., \& Corrigan, S. (1995). Providing information to clients about psychological tests: A survey of attorneys' and law students' attitudes. Professional Psychology: Research and Practice, 26(5), 474-477. http://dx.doi.org/10.1037/0735-7028.26.5.474

Wooley, C. (2013). An Examination of Resnick's Model of Malingering: A PAI Study Of Feigned PTSD. University of North Texas. Retrieved from: http://digital.library.unt.edu/.

Yoxall, J., Bahr, M. \& Barling, N. (2010). Australian psychologists' beliefs and practice in the detection of malingering. In R.E. Hicks (Ed.), Personality and individual differences: Current directions (pp. 315-326). Bowen Hills: Australian Academic Press. Retrieved from: researchgate.net. 